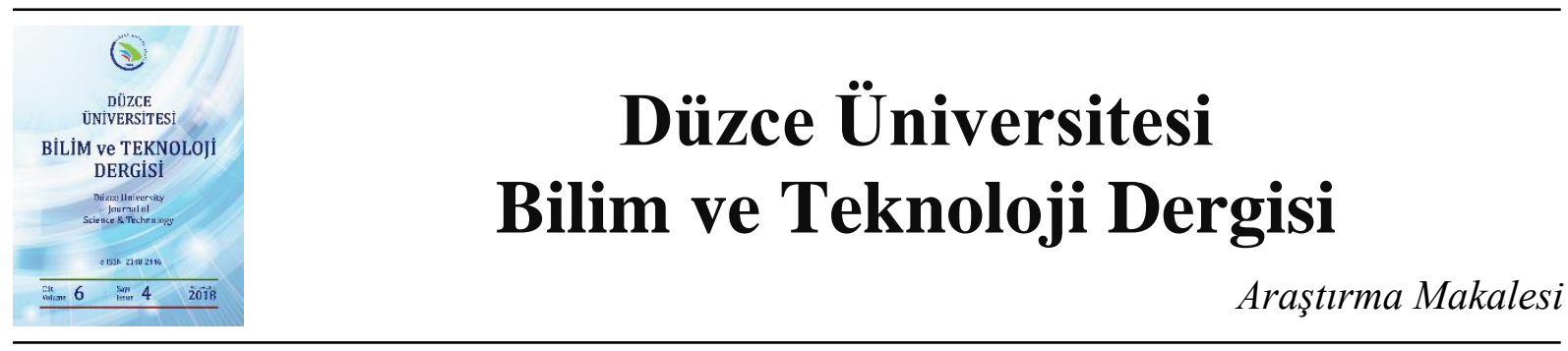

\section{Betonarme Konsol İstinat Duvarlarının Minimum Maliyet ve Ağırlıkla Optimum Tasarımı}

\author{
Hasan Tahsin ÖZTÜRK ${ }^{a, *}$ \\ ${ }^{a}$ İnşaat Mühendisliği Bölümü, Teknoloji Fakültesi, Karadeniz Teknik Üniversitesi, Trabzon, TÜRKIYE \\ * Sorumlu yazarın e-posta adresi: htozturk@ktu.edu.tr
}

\begin{abstract}
ÖZET
Diğer betonarme yapılarda olduğu gibi istinat duvarlarının da geleneksel tasarım süreci, deneme yanılma yöntemini temel almaktadır. Geleneksel tasarımda yönetmelik kriterleri sağlanmaya çalışılmakta, ancak yapının minimum ağırlık ya da minimum maliyetle tasarımı için, mühendislik önsezisi dışında özel bir çaba gösterilememektedir. $\mathrm{Bu}$ çalışmada, bir istinat duvarının optimum tasarımı minimum ağırlık veya minimum maliyet için tek amaç fonksiyonlu ve her ikisi birlikte dikkate alınarak çok amaç fonksiyonlu olarak Jaya algoritmasıyla gerçekleştirilmiştir. Optimum tasarım sonucunda, duvar boyutları ve kesitlerde kullanılacak asal donatılar detaylı olarak belirlenebilmektedir. Çalışmada, ayrıca Jaya algoritmasının bu problem üzerindeki başarımı da incelenmiştir.
\end{abstract}

Anahtar Kelimeler: İstinat duvarl, Maliyet, Ağırllk, Optimizasyon

\section{Optimum Design Reinforced Concrete Cantilever Retaining Walls with Minimum Cost and Weight}

\begin{abstract}
$\underline{\text { ABSTRACT }}$
As in other reinforced concrete structures, the traditional design process of retaining walls is based on the trial and error method. Regulation criteria are tried to be provided in the traditional design, but no special effort can be made except engineering hunch for minimum weight or cost of the structure. In this study, the optimum design of a retaining wall was performed by jaya algorithm as single objective function for minimum weight or cost and as a multi-objective function taking both together. As a result of the optimum design, the wall dimensions and the reinforcement to be used in the critical sections can be determined in details. The study also examines the performance of the algorithm on this cited problem.
\end{abstract}

Keywords: Retaining wall, Cost, Weight, Optimization

Geliş: 20.06.2018, Düzeltme: 01.07.2018, Kabul: 02.07.2018 


\section{GiRiș}

$\mathrm{B}$ etonarme istinat duvarlarının, ülkemizde ve dünyadaki özellikle engebeli bölgelerde sıklıkla kullanılan bayındırlık yapılarından biri olduğu bilinmektedir. Kesitlerinin, ağırlık istinat duvarlarına göre daha küçük olması, kazı maliyetinin düşmesini sağlamakta ve eğilme momenti kapasitelerinin yüksek olması nedeniyle, yatay yüklere daha iyi karşı koyabilmektedirler. Yapısal olarak bu tür duvarlar, gövde ve bir temel plağından oluşmaktadır. Temel plağı ise topuk ve burun kesiti olarak ikiye ayrılabilmektedir.

Bilgisayar yazılım ve donanımlarındaki gelişmeler, bu tür bayındırlık yapılarının, ayrık mühendislik optimizasyon problemi olarak herhangi bir sezgisel algoritmayla çözülmesini ve ayrıntılı tasarımlarını mümkün kılmaktadır. Son yıllarda, betonarme istinat duvarlarının tasarımı konusunda birçok çalışma gerçekleştirilmiştir.

Teknik literatürde, istinat duvarlarının optimum tasarımlarının farklı algoritmalarla gerçekleştirildiği görülmektedir. Bu algoritmalardan bazıları; doğrusal olmayan programlama [1], yüklü sistem arama algoritması [2], benzeşimli tavlama algoritması [3,4], hedef güvenilirlik yaklaşımı [5], çoklu başlangıç değişkenli komşuluk arama eşiği stratejisi [6], harmoni arama [7], büyük patlama büyük çöküş [8], parçacık sürü [9,10], değiştirilmiş parçacık sürü optimizasyon, ateş böceği [11], 1şın optimizasyon yöntemi [12], Levy uçuşları ile biyocoğrafya tabanlı optimizasyon [13], guguk kuşu [11] ve ateş böceği [14] gibi algoritmalardır.

\section{OPTIMIZASYON PROBLEMi}

\section{A. JAYA ALGORITMASI}

Sezgisel bir algoritma olan ve hint dilinde "zafer" anlamına gelen bu algoritma, 2016 y1lında Rao [15] tarafından geliştirilmiştir. Bu algoritma, oluşturulan ve her iterasyonda yenilenen aday çözümler arasından en iyilerine yaklaşmaya ve en kötülerinden uzaklaşmaya çalışarak, belirlenen bir amaç fonksiyonunun en küçükleme ya da en büyüklemesini yapabilmektedir. Algoritmaya ilişkin sözde kod aşağıda verilmektedir.

1: Optimizasyon problemini tanımla, nesil boyutunu ve en büyük iterasyon sayısını gir,

2: En iyi ve en kötü bireyleri belirle,

3: Nesildeki diğer bireyleri, en kötü ve en iyi birey dikkate alınarak yenile (Denklem(1)),

4: Yenilenen birey, eski bireyden daha iyi ise yenilenen bireyle devam et, yenilenen birey eski bireyden daha kötü ise eski bireyle devam et,

5: En büyük iterasyon sayısına ulaşılmamışsa 2. adıma dön, en büyük iterasyon sayısına ulaşılmışsa optimum tasarımı raporla,

6: Bitir.

Algoritmada bireylerin yenilenme işlemi, bireyi oluşturan tasarım değişkenleri için teker teker yapılmaktadır. Bir i. iterasyondaki nesilde bulunan k. bireyin, j. tasarım değişkeni $\left(X_{j, k, i}\right) ; X_{j, e n i y i, i}$ en iyi çözümde $j$. tasarım değişkeninin değeri, $X_{j, \text { enkötü,i }}$ en kötü çözümde $j$. tasarım değişkenini, $r_{1, j, i}$ ve $r_{2, j, i}$ i. iterasyonda j. tasarım değişkeni için $[0,1]$ aralığında üretilen iki rasgele sayıyı göstermek üzere: 
$X_{j, k, i}^{\prime}=X_{j, k, i}+r_{1, j, i}\left(X_{j, e n i y i, i}-\left|X_{j, k, i}\right|\right)-r_{2, j, i}\left(X_{j, \text { enkötü } i, i}-\left|X_{j, k, i}\right|\right)$

ifadesiyle yenilenmektedir. Burada $X_{j, k, i}^{\prime}$ ise $X_{j, k, i}$ nin yenilenen değeridir [15].

\section{B. AMAÇ FONKSIYYONU}

$\mathrm{Bu}$ çalışmada istinat duvarının optimizasyonunda, ağırlık ve/veya maliyetinin minimizasyonu amaçlanmaktadır. Duvar maliyetinin minimizasyonunda kullanılan amaç fonksiyonu:

$$
f_{\text {maliyet }}=M_{d} W_{d t}+M_{b} V_{b} \quad(\$ / m)
$$

olarak ifade edilmektedir. Burada $\mathrm{M}_{\mathrm{d}}$ donatının birim maliyetini $(\$ / \mathrm{kg}), \mathrm{M}_{\mathrm{b}}$ betonun birim maliyetini $\left(\$ / \mathrm{m}^{3}\right), \mathrm{W}_{\mathrm{dt}}$ donatının toplam ağırlığını, $\mathrm{V}_{\mathrm{b}}$ beton hacmini göstermektedir. Duvar ağırlığının en küçüklemesinde kullanılan amaç fonksiyonu ise:

$$
f_{\text {weight }}=W_{d t}+100 \cdot \delta_{c} V_{b} \quad(\mathrm{~kg} / \mathrm{m})
$$

denklemiyle hesaplanmaktadır. Burada $\delta_{\mathrm{c}}$ betonun birim hacim ağılığını göstermektedir. Çalışmada betonun ve donatının birim hacim ağırlıkları sırasıyla $23.5 \mathrm{kN} / \mathrm{m}^{3}$ ve $78.5 \mathrm{kN} / \mathrm{m}^{3}$, beton ve donatının birim maliyetleri ise sırasıyla; $40 \$ / \mathrm{m}^{3}$ ve $0.40 \$ / \mathrm{kg}$ olarak dikkate alınmıştır.

\section{TASARIM DEĞISSKENLERI}

Tasarım değişkenleri, optimizasyon sürecinde, seçilen algoritma tarafından optimum değerlerinin bulunmasının hedeflendiği parametrelerdir. Oluşturulan optimizasyon probleminde, toplam 8 adet tasarım değişkeninin olduğu Şekil 1'den görülmektedir.

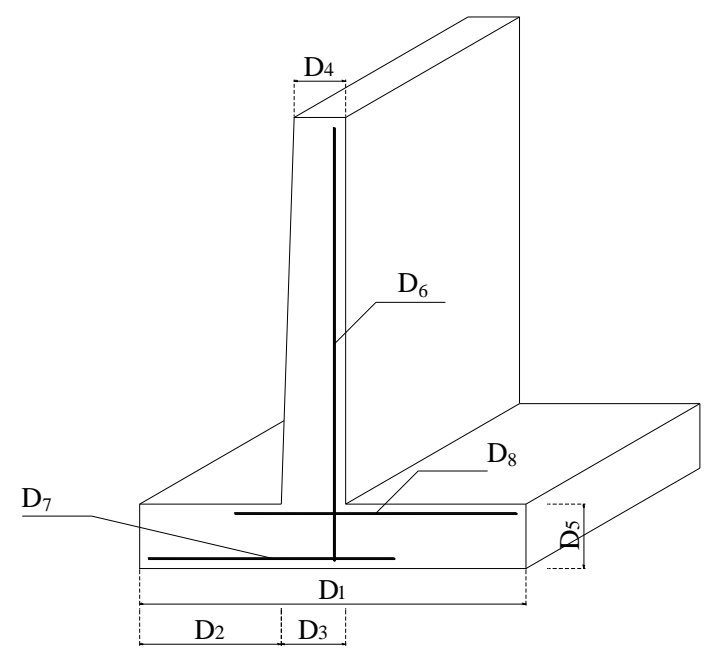

Şekil 1. Istinat duvarı için belirlenen tasarım değişkenleri 
$\mathrm{Bu}$ şekilde, $\mathrm{D}_{1}$ ile ifade edilen tasarım değişkeni temelin toplam genişliğini, $\mathrm{D}_{2}$ ön konsolun (burun) genişliğini, $\mathrm{D}_{3}$ ve $\mathrm{D}_{4}$ sırasıyla gövdenin en alt ve en üst kotundaki genişliğini, $\mathrm{D}_{5}$ temelin kalınlığını, $\mathrm{D}_{6}, \mathrm{D}_{7}$ ve $\mathrm{D}_{8}$ gövde, burun ve topuk kesitlerinde bulunan donatılarla ilgili bilgileri ifade etmektedir. Donatı bilgileri birer indeks numarası ile ifade edilmektedir. Her bir indeks numarası bir donat1 sayısına ve çapına karşılık gelmektedir. Çeşitli donatı sayısı ve çaplarından oluşan bir veri havuzu oluşturulmuştur. Algoritma, bu veri havuzundan indeks numaralarına göre donatı seçimi yapmaktadır. Oluşturulan bu veri havuzu, aşağıdaki Tablo 1'de özet olarak verilmektedir.

Tablo 1. İstinatı duvarı donatıları için oluşturulan veri havuzu

\begin{tabular}{ccc}
\hline $\begin{array}{c}\text { Indeks } \\
\text { No }\end{array}$ & $\begin{array}{c}\text { Donatı Sayıs } \\
(\text { Adet })\end{array}$ & $\begin{array}{c}\text { Donatı Çapı ve } \\
\text { Enkesit Alanı }\end{array}$ \\
\hline 1 & 3 & $10 \mathrm{~mm}\left(235.6 \mathrm{~mm}^{2}\right)$ \\
\hline 2 & 4 & $10 \mathrm{~mm}\left(314.1 \mathrm{~mm}^{2}\right)$ \\
\hline 3 & 3 & $12 \mathrm{~mm}\left(339.2 \mathrm{~mm}^{2}\right)$ \\
\hline 4 & 5 & $10 \mathrm{~mm}\left(392.6 \mathrm{~mm}^{2}\right)$ \\
\hline 5 & 4 & $12 \mathrm{~mm}\left(452.3 \mathrm{~mm}^{2}\right)$ \\
\hline$\ldots$ & $\ldots$ & $\ldots$ \\
\hline$\ldots$ & $\ldots$ & $\ldots$ \\
\hline 221 & 16 & $30 \mathrm{~mm}\left(11309.7 \mathrm{~mm}^{2}\right)$ \\
\hline 222 & 17 & $30 \mathrm{~mm}\left(12016.5 \mathrm{~mm}^{2}\right)$ \\
\hline 223 & 18 & $30 \mathrm{~mm}\left(12723.4 \mathrm{~mm}^{2}\right)$ \\
\hline
\end{tabular}

Problemlerde kullanılan 8 tasarım değişkeninin alt ve üst sınırları, ayrık değişim miktarları ve alabilecekleri değer sayıları, Tablo 2'de verilmektedir.

Tablo 2. İstinat duvarı tasarım değişkenleri alt ve üt sınırları, değişsim miktarları ve değişkenlerin alabileceğ i farklı değer sayıları

\begin{tabular}{ccccc}
\hline $\begin{array}{c}\text { Tasarım } \\
\text { Değişkeni }\end{array}$ & Alt Sınır & Üst Sınır & $\begin{array}{c}\text { Değişim } \\
\text { Miktarı }\end{array}$ & $\begin{array}{c}\text { Alabileceği } \\
\text { Değer Sayısı }\end{array}$ \\
\hline $\mathrm{D}_{1}$ & $1.31 \mathrm{~m}$ & $2.33 \mathrm{~m}$ & 0.01 & 103 \\
\hline $\mathrm{D}_{2}$ & $0.44 \mathrm{~m}$ & $0.78 \mathrm{~m}$ & 0.01 & 35 \\
\hline $\mathrm{D}_{3}$ & $0.20 \mathrm{~m}$ & $0.33 \mathrm{~m}$ & 0.01 & 14 \\
\hline $\mathrm{D}_{4}$ & $0.20 \mathrm{~m}$ & $0.33 \mathrm{~m}$ & 0.01 & 14 \\
\hline $\mathrm{D}_{5}$ & $0.27 \mathrm{~m}$ & $0.33 \mathrm{~m}$ & 0.01 & 7 \\
\hline $\mathrm{D}_{6}$ & İndeks 1 & İndeks 223 & 1 & 223 \\
\hline $\mathrm{D}_{7}$ & İndeks 1 & İndeks 223 & 1 & 223 \\
\hline $\mathrm{D}_{8}$ & İndeks 1 & İndeks 223 & 1 & 223 \\
\hline
\end{tabular}

\section{YAPISAL SINIRLAYICILAR}

İstinat duvarı tasarımının sınırlayıcıları, çeşitli tahkiklerden ve sağlanması gereken geometrik şartlar ve yönetmelik koşullarından oluşmaktadır. Duvarın devrilme tahkiki, $G K_{D}^{\text {hesap }}$ tasarlanan duvar için hesaplanan devrilme güvenlik katsayısını, $G K_{D}$ ise aşılmamak üzere dikkate alınan devrilme güvenlik katsayısını göstermek üzere: 
$\mathrm{g}_{1}(\mathrm{D})=\frac{\mathrm{GK}_{\mathrm{D}}^{\text {hesap }}}{\mathrm{GK}_{\mathrm{D}}}-1 \leq 0$

ifadesiyle, kayma tahkiki ise, $G K_{K}^{\text {hesap }}$ tasarlanan duvar için hesaplanan kayma güvenlik katsayısını, $G K_{K}$ ise aşılmamak üzere dikkate alınan kayma güvenlik katsayısını göstermek üzere:

$$
\mathrm{g}_{2}(\mathrm{D})=\frac{\mathrm{GK}_{\mathrm{K}}^{\text {hesap }}}{\mathrm{GK}_{\mathrm{K}}}-1 \leq 0
$$

ifadesiyle, taşıma gücü tahkiki ise, $G K_{T G}^{\text {hesap }}$ tasarlanan duvar için hesaplanan taşıma gücü güvenlik katsayısını, $G K_{T G}$ ise aşılmamak üzere dikkate alınan taşıma gücü güvenlik katsayısını göstermek üzere:

$$
\mathrm{g}_{3}(\mathrm{D})=\frac{\mathrm{GK}_{\mathrm{TG}}^{\text {hesap }}}{\mathrm{GK}_{\mathrm{TG}}}-1 \leq 0
$$

ifadesiyle denetlenmektedir.

Temel altında oluşan en küçük zemin basıncının $\left(\sigma_{z \min }\right)$ sıfırdan küçük (çekme) olmaması için aşağıdaki denetimin de yapılması gerekmektedir.

$$
g_{4}(D)=-\frac{\sigma_{z \min }}{100} \leq 0
$$

Burada, paydadaki 100 katsayısı sınırlayıcıyı ölçeklemek için kullanılmaktadır.

Gövde, burun ve topuk kritik kesitlerinde elde edilen eğilme momenti $\left(\mathrm{M}_{\mathrm{r}}\right)$ ve kesme kuvveti $\left(\mathrm{V}_{\mathrm{r}}\right)$ taşıma kapasiteleri, söz konusu kesitler için hesaplanan tasarım eğilme momenti $\left(\mathrm{M}_{\mathrm{d}}\right)$ ve kesme kuvvetinden $\left(\mathrm{V}_{\mathrm{d}}\right)$ büyük olmalıdır. Bu denetimler:

$$
\begin{aligned}
& g_{5-7}(D)=\frac{M_{d}}{M_{r}}-1 \leq 0 \\
& g_{8-10}(D)=\frac{V_{d}}{V_{r}}-1 \leq 0
\end{aligned}
$$

ifadeleriyle gerçekleştirilmektedir. Diğer taraftan aynı kritik kesitlere yerleştirilmiş olan asal donatıların oranının $(\rho)$, minimum donatı oranından $\left(\rho_{\text {min }}\right)$ küçük ve maksimum donatı oranından $\left(\rho_{\max }\right)$ büyük olmaması gerekmekte olup, bu oranlar:

$\mathrm{g}_{11-13}(\mathrm{D})=\frac{\rho_{\min }}{\rho}-1 \leq 0$ 


$$
\mathrm{g}_{14-16}(\mathrm{D})=\frac{\rho}{\rho_{\max }}-1 \leq 0
$$

ifadeleriyle denetlenmektedir. Burada minimum ve maksimum donatı oranı sınırlarının, ACI 318 [16] yönetmeliğine göre hesaplandığı belirtilmelidir. Donatı uzunluklarının belirlenmesinde, diğer bir parametre de kenetlenme boylarının hesabidır. Kenetlenme boylarının belirlenmesi, toplam donatı uzunluklarının ve dolayısıyla da donatı ağırlıklarının hesaplanması için gerekli olmaktadır. Tasarımın uygulanabilir olabilmesi için hesaplanan kenetlenme boylarının kesit içerisine yerleşebilmesi gerekmektedir. Kenetlenme boyları kancalı ya da düz kenetlenme yapılacak şekilde ayrı ayrı hesaplanmaktadır. Seçilen kesit için her iki durum da uygun oluyorsa, daha az donatı gerektiren kenetlenme şekli seçilmektedir. Gövde asal donatısının kancalı ve düz kenetlenme durumlarının şematik gösterimi, Şekil 2'de verilmektedir.

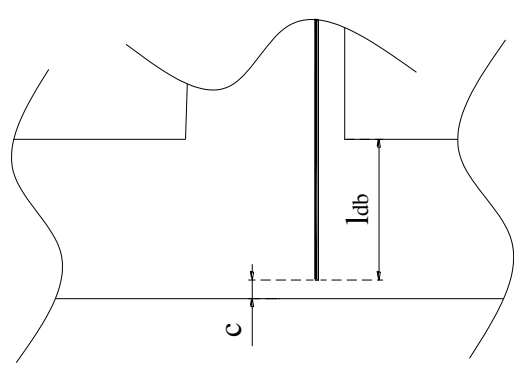

Düz kenetlenme durumu

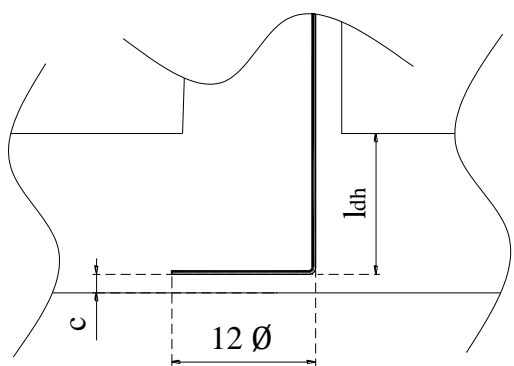

Kancalı kenetlenme durumu

Şekil 2. İstinat duvarı gövde asal donatısinın kenetlenme biçimleri

$\mathrm{Bu}$ iki durum için oluşturulan sınırlayıcılar ise:

$$
\mathrm{g}_{17}(\mathrm{D})=\frac{1_{\mathrm{db}}}{\mathrm{D}_{5}-\mathrm{c}}-1 \leq 0 \quad \text { yada } \quad \mathrm{g}_{17}(\mathrm{D})=\frac{1_{\mathrm{dh}}}{\mathrm{D}_{5}-\mathrm{c}}-1 \leq 0
$$

bağıntıları ile ifade edilmektedir. Ön konsol asal donatısının kancalı ve düz kenetlenme durumlarının şematik gösterimi, Şekil 3 'te verilmektedir.

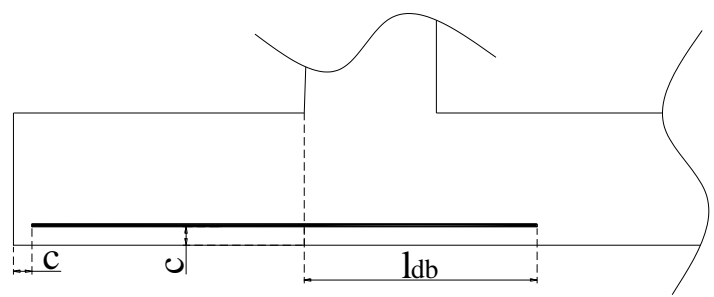

Düz kenetlenme durumu

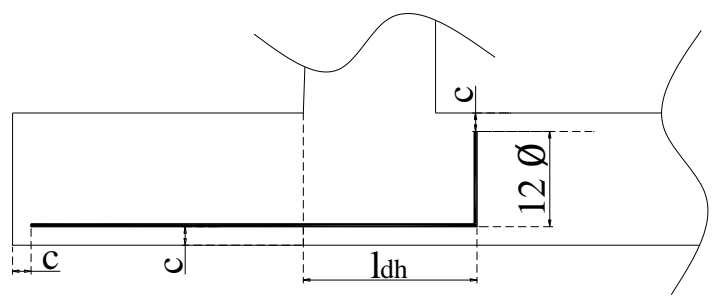

Kancalı kenetlenme durumu

Şekil 3. İstinat duvarı temel ön konsolu asal donatısının kenetlenme biçimleri 
$\mathrm{Bu}$ iki durum için oluşturulan sınırlayıcılar ise:

$$
\mathrm{g}_{18}(\mathrm{D})=\frac{1_{\mathrm{db}}}{\mathrm{D}_{1}-\mathrm{D}_{2}-\mathrm{c}}-1 \leq 0 \quad \text { ya da } \quad \mathrm{g}_{18}(\mathrm{D})=\frac{12 \varnothing}{\mathrm{D}_{5}-\mathrm{c}}-1 \leq 0
$$

bağlantıları ile ifade edilmektedir. Arka konsol asal donatısının kancalı ve düz kenetlenme durumlarının şematik gösterimi ise, Şekil 4'te verilmektedir.
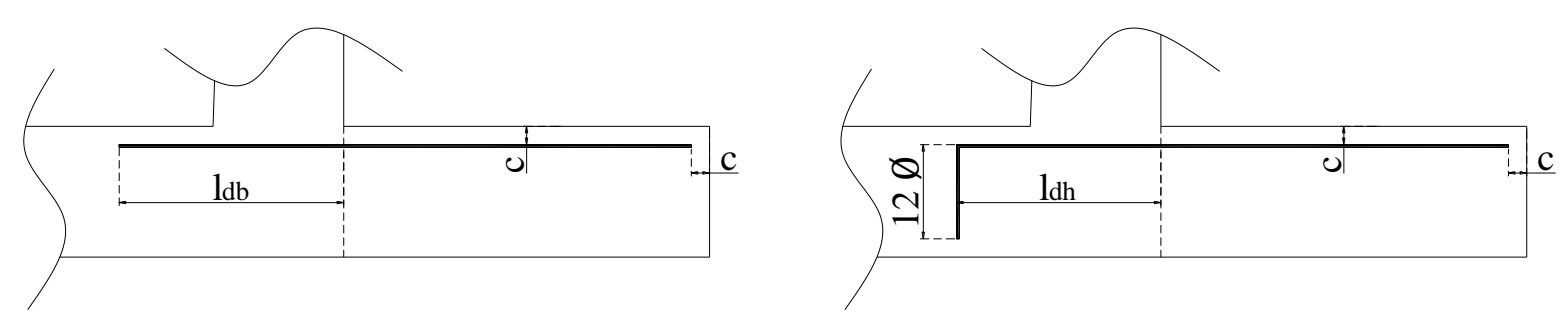

Şekil 4. İstinat duvarı temel arka konsolu asal donatısının kenetlenme biçimleri

Bu iki durum için oluşturulan sınırlayıcılar ise:

$$
\mathrm{g}_{19}(\mathrm{D})=\frac{1_{\mathrm{db}}}{\mathrm{D}_{2}+\mathrm{D}_{3}-\mathrm{c}}-1 \leq 0 \quad \text { yada } \quad \mathrm{g}_{19}(\mathrm{D})=\frac{12 \emptyset}{\mathrm{D}_{5}-\mathrm{c}}-1 \leq 0
$$

bağıntıları ile ifade edilmektedir. Bu bağlantılarda; c net beton örtüsünü, $\varnothing$ asal donatı çapını, $1_{\mathrm{db}}$ düz kenetlenme boyunu, $1_{\mathrm{dh}}$ kancalı kenetlenme durumunda asal donatı doğrultusunda uzatılan donatı boyunu göstermektedir.

Son olarak, seçilen tasarım değişkenlerine göre temel boyutlarının tutarlı olmasını sağlayan geometrik bir sınırlayıcı da kullanılmıştır. Söz konusu bu sınırlayıcı ile, $\mathrm{D}_{1}$ ile ifade edilen temel genişliğinin, ön konsol ile gövde genişliğinin toplamından $\left(D_{2}+D_{3}\right)$ büyük olması sağlanmaktadır. Söz konusu geometrik sinırlayıc1

$$
g_{20}(D)=\frac{D_{2}+D_{3}}{D_{1}}-1 \leq 0
$$

ifadesiyle gösterilmektedir.

\section{SAYISAL UYGULAMA}

İlk olarak, JAYA algoritması kullanılarak seçilen bir istinat duvarının minimum maliyet veya ağırlıkla tek amaç fonksiyonlu olarak optimum tasarımları gerçekleştirilmiş, daha sonra maliyet ve ağırlık amaç fonksiyonları birlikte dikkate alınarak, aynı problem çok amaçlı olarak çözülmüştür. Tek amaç fonksiyonlu optimizasyonlarda, 100'er bağımsız koşum gerçekleştirilmiştir. Seçilen örnekte; duvar yüksekliği $3 \mathrm{~m}$., duvar arkasındaki şev eğimi $10^{\circ}$, duvar arkasındaki zeminin içsel sürtünme açısı $36^{\circ}$, zemin birim hacim ağırlığ $17.5 \mathrm{kN} / \mathrm{m}^{3}$, temel zemininin birim hacim ağırlığ $18.5 \mathrm{kN} / \mathrm{m}^{3}$, temel zemininin kohezyonu $125 \mathrm{kPa}$, burun üzerindeki zemin kalınlığı $0.5 \mathrm{~m}$, sürşarj yükü $20 \mathrm{kPa}$, yük katsayısı 1.7, beton örtüsü $70 \mathrm{~mm}$, betonun basınç dayanımı $21 \mathrm{MPa}$, donatının akma dayanımı 400 
$\mathrm{MPa}$, rötre ve sıcaklık değişimi donatısı oranı 0.002 olarak alınmıştır. İstinat duvarının; devrilme, kayma ve zemin taşıma gücü denetimlerinde aşılmaması gereken güvenlik katsayıları sırasıyla; 1.5, 1.5 ve 3.0 olarak dikkate alınmıştır. Algoritma, MATLAB yazılımında kodlanmıştır. Sınırlayıcıların optimizasyon problemine tanıtılmasında, ceza fonksiyonu yöntemi kullanılmıştır.

Daha önce de belirtildiği gibi, istinat duvarı problemi, öncelikle minimum maliyet ve ağırlık için ayrı ayrı JAYA algoritmasıyla tek amaç fonksiyonlu olarak çözülmüştür. Bu çözümlerin her birinde 100'er bağımsız koşum gerçekleştirilmiştir. Her bir koşumda, 120080 amaç fonksiyonu değerlendirmesi yapılmıştır. Bu koşumlardan elde edilen en iyi, en kötü, ortalama maliyet ve ağırlık değerleriyle bu değerlerin standart sapmaları ve başarım oranları, Tablo 3 'te verilmektedir. Başarım oranı, bağımsız koşullarda global minimuma ulaşılabilen koşum oranını ifade etmektedir. Diğer taraftan, global minimuma ulaşılan amaç fonksiyonu değerlendirme sayılarının en iyi, en kötü ortalama değerleri ve bu değerlerin standart sapmaları da yine Tablo 3'te verilmektedir. Burada, global minimuma ulaşılamayan koşumlarda, bu koşullara ilişkin amaç fonksiyonu değerlendirme sayısının maksimum değer olan 120080 olarak alındığı belirtilmelidir.

Tablo 3. Koşumlardan elde edilen en iyi, en kötü, ortalama maliyet ve ă̆ırlık dĕgerleriyle bu değerlerin standart sapmaları, başarım oranları, amaç fonksiyonu değerlendirme sayılarının en iyi, en kötü ortalama değerleri ve bu değerlerin standart sapmalarl

\begin{tabular}{lcc}
\hline & $\begin{array}{c}\text { Ăğırlık } \\
\text { Optimizasyonu }\end{array}$ & $\begin{array}{c}\text { Maliyet } \\
\text { Optimizasyonu }\end{array}$ \\
\hline En iyi değer & $2684.697(\mathrm{~kg} / \mathrm{m})$ & $72.277(\$ / \mathrm{m})$ \\
\hline Ortalama değer & $2687.058(\mathrm{~kg} / \mathrm{m})$ & $72.436(\$ / \mathrm{m})$ \\
\hline En kötü değer & $2892.459(\mathrm{~kg} / \mathrm{m})$ & $77.625(\$ / \mathrm{m})$ \\
\hline Standart sapma & $20.940(\mathrm{~kg} / \mathrm{m})$ & $0.757(\$ / \mathrm{m})$ \\
\hline Başarım oranı & $\% 98$ & $\% 80$ \\
\hline En iyi AFDS & 45280 & 19760 \\
\hline Ortalama AFDS & 70627 & 51513 \\
\hline En kötü AFDS & 120080 & 120080 \\
\hline AFDS Standart sapması & 15843 & 36454 \\
\hline *AFDS: Amaç fonksiyonu değerlendirme sayısı & & \\
\hline
\end{tabular}

Tablo 3'ten jaya algoritması ile maliyet optimizasyonundan duvarın maliyetinin $72.277 \$ / \mathrm{m}$ olarak elde edildiği görülmektedir. Aynı algoritma ile gerçekleştirilen ağırlık optimizasyonundan, duvarın ağırlığı $2684.697 \mathrm{~kg} / \mathrm{m}$ olarak elde edilmiştir. Maliyet optimizasyonunda başarım oranının \% 80, ağırlık optimizasyonunda ise \% 98 olduğu belirlenmiştir. Diğer bir deyişle, maliyet optimizasyonunda jaya algoritması, 100 bağımsız koşumun \%80'sinde, ağırlık optimizasyonunda ise \%98'sinde global minimuma ulaşabilmiştir. Diğer taraftan, amaç fonksiyonu değerlendirme sayısının ortalaması, maliyet optimizasyonu için 51513 iken, ağırlık optimizasyonu için ise 70627 olarak belirlenmiştir. Bu durum, ağırlık optimizasyonunda başarım oranının yüksek olmasına rağmen global minimuma ulaşılan ortalama amaç fonksiyonu değerlendirme sayısının, maliyet optimizasyonundakinden daha yüksek olduğunu göstermektedir. Buradan, ağırlık optimizasyonundaki yakınsamanın daha yavaş olduğu, ancak algoritmanın global optimuma ulaşabilmede daha başarılı olduğu anlaşılmaktadır.

Jaya algoritmasıyla gerçekleştirilen ağırlık ve maliyet optimizasyonu sonucunda elde edilen optimum tasarım değişkenlerinin şematik gösterimleri ise Şekil 5’te verilmektedir. 


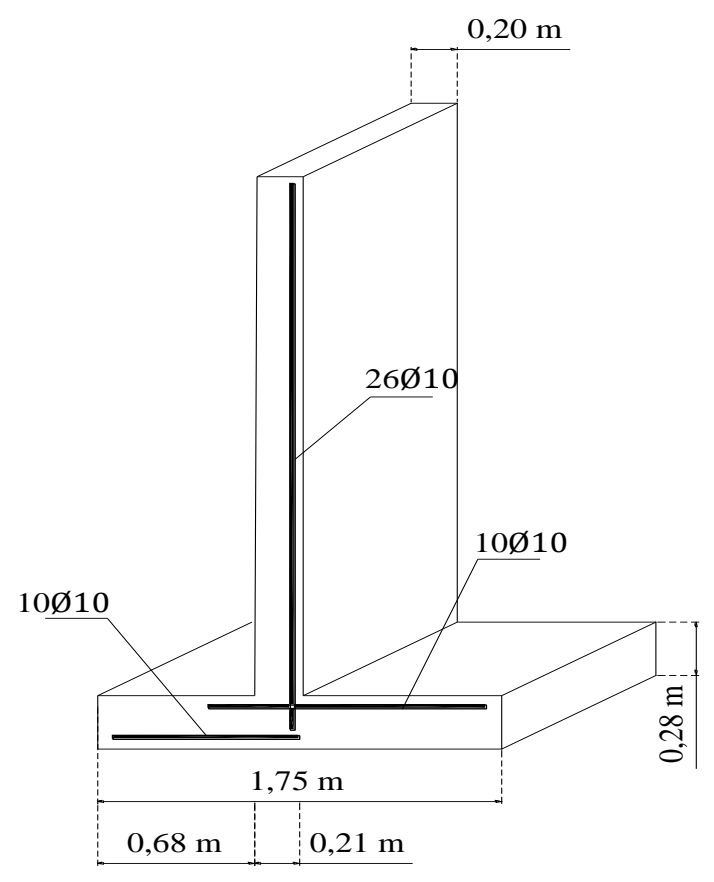

Minimum Ağırlıklı Tasarım

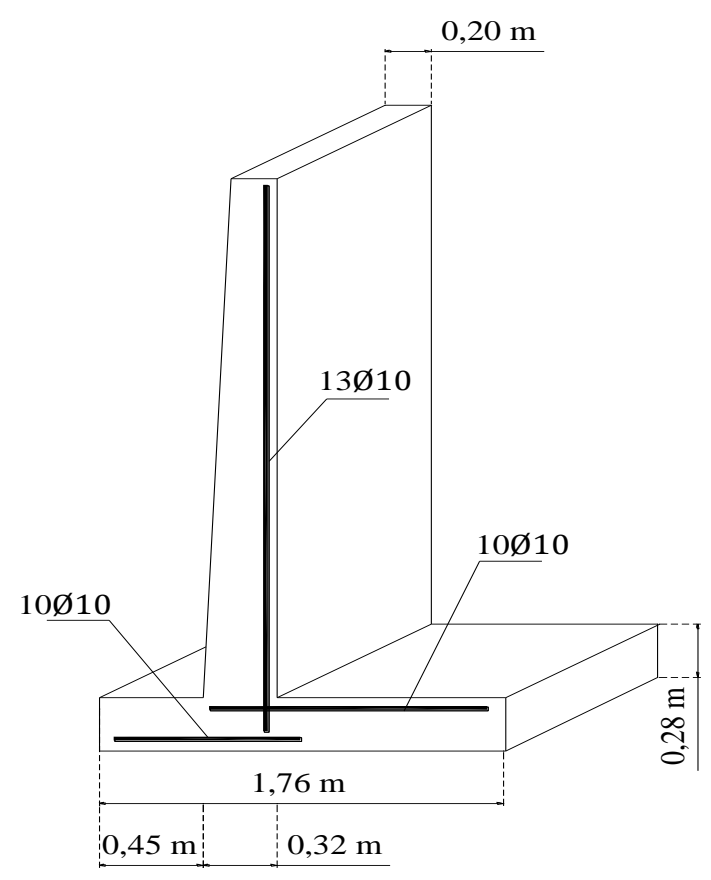

Minimum Maliyetli Tasarım

Şekil 5. Minimum ă̆ırlıklı ve maliyetli tasarımların şematik gösterimi

$\mathrm{Bu}$ problemin Jaya algoritması ile çok amaçlı optimizasyonu için ise, ağırlıklandırılmış toplama yöntemi kullanılmıştır. İstinat duvarının maliyetine göre ağırlığının minimum değerlerini değişimini gösteren pareto çözümler, Şekil 6'da gösterilmektedir.

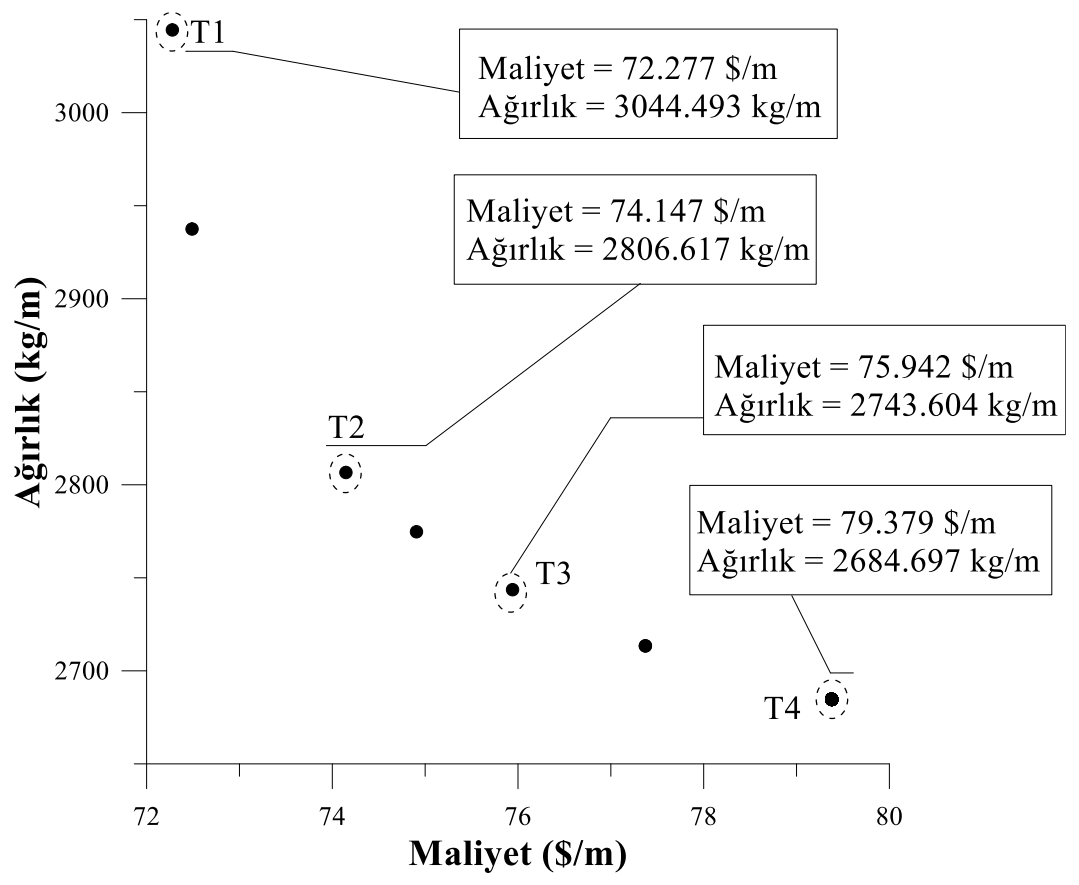

Şekil 6. Çok amaçlı optimizasyonda pareto çözüm grafiği 
Şekil 6'dan, pareto çözümlerin uygun bir dağılım gösterdiği anlaşılmaktadır. Pareto çözümlerden elde edilen farklı tasarımları karşılaştırmak için dört karakteristik tasarım seçilmiştir ve bu tasarımlar grafik üzerinde T1, T2, T3 ve T4 noktaları ile ifade edilmiştir. Bu noktaların maliyet ve ağırlık değerleri de şekil üzerinde gösterilmiştir. Grafikteki T1 ve T4 noktalarına karşılık gelen tasarımlar, uç tasarımları göstermektedir. Bunlardan T1 tasarımı amaç fonksiyonunun minimum maliyet seçildiği optimizasyona, T4 tasarımı ise amaç fonksiyonunun minimum ağırlık seçildiği optimizasyona karşılık gelmektedir. T2 ve T3 tasarımları ise elde edilen pareto sonuçlardan rastgele seçilen iki tasarımı göstermektedir. Uç tasarımlar olan T1 ve T4 tasarım arasında maliyet artışının yaklaşık olarak \%10 ve yine bu iki tasarım arasında ağırlık artışının ise yaklaşık olarak \%14 olduğu görülmektedir.

\section{SONUC}

$\mathrm{Bu}$ çalışmada, sezgisel bir algoritma olan Jaya algoritması kullanılarak betonarme konsol bir istinat duvarının optimum tasarımı gerçekleştirilmiştir. Gerçekleştirilen tasarımlarda, öncelikle amaç fonksiyonu olarak minimum maliyet ve minimum ağırlık ayrı ayrı dikkate alınmıştır. Yapılan koşumlardan elde edilen bulgular, ağırlık optimizasyonu için başarım oranının maliyet optimizasyonuna göre daha yüksek olduğunu göstermiştir. Bununla birlikte ağırlık optimizasyonunun, maliyet optimizasyonu ile karşılaştırıldığında başarım oranının yüksek olmasına rağmen, ortalama amaç fonksiyonu değerlendirme sayısının daha yüksek olduğu belirlenmiştir. Buradan ağırlık optimizasyonunda yakınsamanın daha yavaş olduğu, ancak algoritmanın global optimuma ulaşabilmede daha başarılı olduğu sonucuna varılmıştır. Daha sonra, ağırlık ve maliyet amaç fonksiyonları birlikte dikkate alınarak aynı problem, çok amaç fonksiyonlu olarak tekrar çözülmüştür. $\mathrm{Bu}$ çözüm sonucunda, pareto noktalar elde edilerek çok amaçlı optimizasyon için pareto dağılım grafiği tutarlı bir şekilde elde edilmiştir.

TEŞEKKÜR: Bu çalışma Karadeniz Teknik Üniversitesi Bilimsel Araştırma Projeleri Birimi tarafından desteklenmiştir (Proje no: FBB-2015-130)

\section{KAYNAKLAR}

[1] A. Saribas ve F. Erbatur, "Optimization and Sensitivity of Retaining Structures", Journal of Geotechnical Engineering, c. 122, s.8, ss. 649-656, 1996.

[2] A. Kaveh ve A.F. Behnam, "Charged System Search Algorithm for the Optimum Cost Design of Reinforced Concrete Cantilever Retaining Walls", Arabian Journal for Science and Engineering, c. 38, s. 3, ss. 563-570, 2013.

[3] B. Ceranic, C. Fryer ve R.W. Baines, "An Application of Simulated Annealing to the Optimum Design of Reinforced Concrete Retaining Structures", Computers \& Structures, c. 79, s. 17, ss. 1569-1581, 2001.

[4] V. Yepes, J. Alcala, C. Perea ve F. González-Vidosa, "A Parametric Study of Optimum EarthRetaining Walls by Simulated Annealing”, Engineering Structures, c. 30, s. 3, ss. 821-830, 2008. 
[5] G.L. Sivakumar Babu ve B.M. Basha, "Optimum Design of Cantilever Retaining Walls Using Target Reliability Approach”, International Journal of Geomechanics, c. 8, s. 4, ss. 240-252, 2008.

[6] V. Yepes, F. Gonzalez-Vidosa, J. Alcala ve P. Villalba, " $\mathrm{CO}_{2}-$ Optimization Design of Reinforced Concrete Retaining Walls Based on a VNS-Threshold Acceptance Strategy", Journal of Computing in Civil Engineering, c. 26, s. 3, ss. 378-386, 2011.

[7] A. Akin, ve M.P. Saka, "Optimum Design of Concrete Cantilever Retaining Walls using Harmony Search Algorithm". $9^{\text {th }}$ International Congress on Advances in Civil Engineering, Trabzon, 2010.

[8] C.V. Camp ve A. Akin, "Design of Retaining Walls Using Big Bang-Big Crunch Optimization”, Journal of Structural Engineering, c. 138, s. 3, ss. 438-448, 2011.

[9] A.H. Kayhan ve A. Demir, "Betonarme Konsol Istinat Duvarlarının Parçacık Sürü Optimizasyonu ile Optimum Tasarımı”, Pamukkale Üniversitesi Mühendislik Bilimleri Dergisi, c. 22, s. 3, ss. 129-135, 2016.

[10] A.H. Gandomi, A.R. Kashani, D.A. Roke ve M. Mousavi, "Optimization of Retaining Wall Design using Recent Swarm Intelligence Techniques", Engineering Structures, c. 103, ss. 72-84, 2015.

[11] M. Khajehzadeh, M.R. Taha, A. El-Shafie ve M. Eslami, "Modified Particle Swarm Optimization for Optimum Design of Spread Footing and Retaining Wall", Journal of Zhejiang University-Science A, c. 12, s. 6, ss. 415-427, 2011.

[12] A. Kaveh, ve M. Khayatazad, "Optimal Design of Cantilever Retaining Walls using Ray Optimization Method", Iranian Journal of Science and Technology Transactions of Civil Engineering, c. 38 , s. C1+, ss. $261-274,2014$.

[13] I. Aydogdu, "Cost Optimization of Reinforced Concrete Cantilever Retaining Walls under Seismic Loading using a Biogeography-Based Optimization Algorithm with Levy Flights", Engineering Optimization, c. 49, s. 3, ss. 381-400, 2017.

[14] M. Khajehzadeh, M.R. Taha ve M. Eslami, "A New Hybrid Firefly Algorithm for Foundation Optimization”, National Academy Science Letters, c. 36, s.3, ss. 279-288, 2013.

[15] R. Rao, "Jaya: a Simple and New Optimization Algorithm for Solving Constrained and Unconstrained Optimization Problems", International Journal of Industrial Engineering Computations, c. 7, s. 1, ss. 19-34, 2016.

[16] Building Code Requirements for Structural Concrete and Commentary, ACI Committee, ACI 318, 2014. 